\title{
Rapidly Evolving Deep Dissecting Hematoma With Sudden Onset, Developed One Month After A Minimal Trauma.
}

Rémy Hamdan ( $\nabla$ remy.hamdan@gmail.com )

CHU Dijon: Centre Hospitalier Universitaire de Dijon https://orcid.org/0000-0002-5207-9393

Narcisse Zwetyenga

CHU Dijon: Centre Hospitalier Universitaire de Dijon

Yvan Macheboeuf

CHU Dijon: Centre Hospitalier Universitaire de Dijon

Patrick Ray

CHU Dijon: Centre Hospitalier Universitaire de Dijon

\section{Case report}

Keywords: dermatoporosis, deep dissecting hematoma, Vitamin K antagonist, Ultrasound Doppler.

Posted Date: September 29th, 2021

DOI: https://doi.org/10.21203/rs.3.rs-889457/v1

License: (c) (i) This work is licensed under a Creative Commons Attribution 4.0 International License. Read Full License 


\section{Rapidly Evolving Deep Dissecting Hematoma With Sudden Onset,}

\section{Developed One Month After A Minimal Trauma.}

Authors: Rémy Hamdan MD*, Narcisse Zwetyenga MD PhD \$, Yvan Macheboeuf MD \$, Patrick Ray MD PhD $\uparrow$

* Department of Angiology, Dijon Bourgogne University Hospital

$\dagger$ Department of Emergency Medicine, Dijon Bourgogne University Hospital

* Department of Plastic Reconstructive and Hand Surgery, Department of Oral and Maxillofacial Surgery, Dijon Bourgogne University Hospital

Corresponding author:

- Dr Rémy Hamdan, Service d'Angiologie, CHU de Dijon - 14, rue Paul Gaffarel - 21000 Dijon, France. Email: remy.hamdan@gmail.com. Telephone: +33.3.80.29.34.09.

Listed authors:

- Pr Narcisse Zwetyenga, Service de chirurgie maxillo-faciale et chirurgie plastique, CHU de Dijon - 14, rue Paul Gaffarel - 21000 Dijon, France. E-mail: narcisse.zwetyenga@chu-dijon.fr. Telephone: +33.3.80.29.37.57

- Dr Yvan Macheboeuf, Service de chirurgie maxillo-faciale et chirurgie plastique, CHU de Dijon - 14, rue Paul Gaffarel - 21000 Dijon, France. E-mail: yvan.macheboeuf@gmail.com. Telephone: +33.3.80.29.37.57

- Pr Patrick Ray, Centre Régional Universitaire des Urgences, CHU de Dijon - 14, rue Paul Gaffarel-21000Dijon, France.E-mail: patrick.ray@chu-dijon.fr. Telephone: $+33.3 .80 .29 .53 .04$

Professional writing assistance: Mrs. Suzanne Rankin, Translation-Reading English, Delegation for Clinical Research and Innovation (DRCI). Email: Suzanne.rankin@chudijon.fr. Telephone: +33.3 .80 .29 .50 .15$ 


\section{Abstract}

Background: Deep dissecting hematoma is a rapidly extending blood collection that splits the hypodermis from muscle fascia, constituting a medical surgical emergency. The natural history of this condition includes trauma (even minor physical injury) shortly before onset of the lesion, occurring in a patient with advanced dermatoporosis.

Case presentation: We report the admission of a 70-year-old woman to the emergency department of our hospital for the onset of a deep dissecting hematoma one month after a negligible trauma in the right leg, complicating secondary iatrogenic dermatoporosis. Bedside ultrasound examination was used to eliminate differential or additional diagnoses and to assess the main features of the hematoma (dimensions, existence of blood supply). Surgical debridement and hematoma drainage were performed due to rapid horizontal extension of the hematoma and unresolved pain, with the operative report confirming the diagnosis. Conclusion: This observation emphasises that in patients with severe dermatoporosis, several weeks can elapse between a minor impact and the sudden development of a limb-threatening deep dissecting hematoma.

Keywords: dermatoporosis, deep dissecting hematoma, Vitamin $\mathrm{K}$ antagonist, Ultrasound Doppler.
\end{abstract}

\title{
Background
}

Deep dissecting hematoma (DDH) is the pooling of blood under pressure which rapidly dissects the virtual space between the fascia muscle and the hypodermis $(1,2)$. It represents the most serious stage of dermatoporosis. Prompt management is needed to minimize the risk of secondary skin necrosis. DDH is caused by profuse bleeding from fragile superficial vessels. Like intramural hematoma in acute aortic syndromes, dissection provoked by blood under pressure between two splitting layers extends the lesion(1). 
The diagnosis of DDH is clinical. It is classically a hematoma extending rapidly in a patient affected by dermatoporosis, arising forthwith after a trauma. Medical imaging (magnetic resonance imaging $[\mathrm{MRI}]$, computed tomography scan or ultrasonography) is sometimes required to confirm the diagnosis $(1,2)$, especially when medical history fails to explain the onset of the lesion. Long periods of time between the initial trauma and the appearance of a hematoma, which is a main feature in chronic expanding hematoma(3), has seldom been reported for DDH(4-6). We report a case of a right-leg pretibial DDH occurring one month after a minor trauma.

\section{Case presentation}

A 70-year-old woman was referred to our emergency department with a sizeable pretibial hematoma located in the outer aspect of the back of the lower right leg, ending just above the ankle (figure 1). The patient's body mass index (BMI) was $20.7 \mathrm{~kg} / \mathrm{m}^{2}$, blood pressure 147/96 $\mathrm{mmHg}$, heart rate $101 \mathrm{bpm}$, and temperature $36.5^{\circ} \mathrm{C}$. No clinical signs were in favour of erysipelas. Neither weakness nor paraesthesia was observed. Pedis and posterior tibial pulse palpation was limited due to hematoma. Skin examination revealed senile purpura, atrophy, large lacerations and superficial haematomas located in the forearms.

After a minor trauma a month prior, a limited superficial hematoma developed. On the day of admission to the emergency department in the morning, rapid extension of the initial superficial hematoma occurred suddenly, reaching the feet and the upper calf, associated with pain, preventing weight bearing on the affected limb.

Medical history included severe comorbidities:

- $\quad$ sarcoidosis treated by prednisone $8 \mathrm{mg}$ /day for more than ten years,

- WHO Group III pulmonary hypertension treated by fluindione $20 \mathrm{mg} /$ day for three years,

- chronic respiratory insufficiency treated with long term oxygen inhalation therapy, 
- smoking cessation several years previously,

- osteoporosis highlighted by dual-energy x-ray absorptiometry two years previously,

- arrythmia and hypothyroidism,

- other daily treatments included bosentan, furosemide, levothyroxine sodium, a fixed dose combination of fluticasone propionate and salmeterol for inhalation, potassium chloride and estradiol patches.

Blood testing revealed: white blood cell count, $12.10 / \mu \mathrm{L}$ (with neutrophils: $10.30 / \mu \mathrm{L}$ ); normal platelet count; haemoglobin, $13.40 \mathrm{~g} / \mathrm{dl}$; C-reactive protein, $7.50 \mathrm{mg} / \mathrm{L}$ and estimated glomerular filtration rate, $93 \mathrm{~mL} / \mathrm{min}$ per $1.73 \mathrm{~m}^{2}$. The international normalized ratio (INR) was 3.15 .

X-ray at admission showed no underlying bone fracture. An arterial and venous Doppler ultrasound (US) examination found that ilio-femoral-popliteal arterial axes were patent with triphasic flow from common iliac to plantar arteries, and there was no evidence for recent deep vein thrombosis (DVT). Soft tissue study revealed a hypo/heterogenous well-delineated mass located between skin and fascia (figure 2). Initial medical management involved fluindione discontinuation, administration of $5 \mathrm{mg}$ of vitamin $\mathrm{K}$ and analgesics. The patient's pain was relieved when the haematoma spontaneously opened. The day after, surgical treatment consisted in debridement, and hematoma drainage in aseptic conditions under rachianesthesia. A bulky hematoma (15 x $20 \mathrm{~cm}$ with 5-6 cm thickness) localized between the fascia muscle and hypodermis was noted, confirming the diagnosis of DDH.

Two units of packed red blood cells were transfused the day following surgery. Postoperative management included analgesia and daily local care including mechanical debridement and dressings. Biological examination of surgical samples found numerous red blood cells and no leukocytes. Bacteriological analyses were sterile. 
The hospital stay lasted thirteen days. Clinical and biological follow-up revealed a 4.5 kilogram-weight loss (two months after surgery) and depressive mood, hypoalbuminemia (CRP-corrected albumin less than $30 \mathrm{mg} / \mathrm{l}$ ) and chronic anaemia. Wound healing was obtained spontaneously after three months without surgery for a skin graft.

\section{Discussion}

To our knowledge, DDH usually arises immediately after an injury, often a minor one $(2,5,7-$ 9). Data concerning the prevalence and incidence of DDH are rare. A monocentric retrospective review found an incidence rate of 53\% $(95 \% \mathrm{CI}=44.64)$ per year. Among 112 hematomas observed during the three-year study period, 26 were $\mathrm{DDH}(5)$. The differential diagnoses include erysipelas, DVT, non-dissecting hematoma and Morel-Lavallee syndrome (serolymphatic effusion caused by tangential trauma to a highly vascularized tissue) $(2,4)$. Uncommon aetiologies should not be overlooked(6,9).

Dermatoporosis is a chronic phenomenon where the skin becomes frail and tears easily(10). A French cross-sectional study including 202 hospitalized patients aged 60 years and older found that the prevalence of dermatoporosis in their population was $32 \%(11)$. Primary dermatoporosis, resulting from chronological aging and long-term sun exposure, is the most commonly encountered type. Secondary dermatoporosis is due to exogenous factors weakening the skin, mainly chronic use of topical and systemic steroids.

Depending on the extension, age and whether or not the haematoma is closed, Fennira et al. described four types of DDH (early closed type, advanced closed, advanced type with necrosis and open type) and highlighted rapid increase in the volume and extent of the haematoma as signs of severity(2). In addition, although it has been reported under direct oral anticoagulants(9), the association of skin frailty and vitamin $\mathrm{K}$ antagonists (for which cutaneous 
complications are well documented(8)) or antiplatelet drugs(4) remains the classical situation where DDH has been observed(1,5).

In our case, it is quite clear that the clinical manifestations of dermatoporosis were secondary to long-term corticosteroid therapy. Differential diagnoses were eliminated by clinical examination, Doppler ultrasound and biological analyses.

According to Kayak et al., at advanced stages of dermatoporosis, where there is a loss of the skin's viscoelastic properties, a "fracture" of the dermis may occur after minor trauma, leading to $\mathrm{DDH}(10)$. In our case, in all likelihood, a negligible trauma caused a superficial hematoma which did not resorb (favoured by anticoagulation therapy) and decompensated spontaneously into DDH (due to dermis fragility) after a one-month quiescent phase. Then, an early-closed type DDH progressed to an advanced closed type and then an open type, all within a few hours.

In Kaya et al., all patients had an MRI to assess the extension of the lesion, described as a bright structure between the muscular fascia and hypodermis(1). MRI is a highly useful examination but with limited accessibility in emergency settings. Ultrasound is more easily accessed, but the results depend on the operator's level of skill. In this case, management included a bedside ultrasound scan which provided valuable information (the depth of the hematoma, blood supply) allowing the medical team to rule out the differential diagnoses and to evaluate the prognosis for wound healing. Few studies have reported the utility of bedside ultrasound examination in this context(12).

\section{Conclusion}

DDH constitutes the most serious stage of dermatoporosis. Considering the benefit of early treatment, emergency department staff should be able to rapidly recognize this type of hematoma. A long interval may be possible between the initial minor trauma and the rapid extension of the lesion, constituting a diagnostic challenge for the treating physician. To our 
knowledge, in the few studies focused on DDH, none have highlighted this issue of time. We report a case of DDH appearing one month after a minor trauma, complicating iatrogenic secondary dermatoporosis in an acute mode, and prompting medical surgical management.

Abbreviations: DDH: Deep Dissecting hematoma; MRI: Magnetic Resonance Imaging

Acknowledgment: Ms. Suzanne Rankin is to be thanked for proofreading this document and making the necessary corrections.

Authors' contributions: RH: collection of data, drafting and critical review of the literature and critical revision. PR: critical revision. NZ: critical revision. YM: critical revision. All authors read and approved the final manuscript.

Funding: The authors declare that they received no funding.

Availability of data and materials: All data generated or analyzed during this study are included in this published article.

\section{Declarations}

Ethics approval and consent to participate: Ethics approval and consent were waived because this study is se report.

Consent for publication: The patient gave consent for publication.

Competing interests: All authors declare that they have no competing interests.

\section{References}

1. Kaya G, Jacobs F, Prins C, Viero D, Kaya A, Saurat J-H. Deep Dissecting Hematoma: An Emerging Severe Complication of Dermatoporosis. Arch Dermatol [Internet]. 2008 Oct 1 [cited 2020 Dec 12];144(10). Available from: https://doi.org/10.1001/archderm.144.10.1303

2. Fennira F, Colboc H, Meaume S. Dissecting haematoma, a frequent but little-known pathology. Revue Francophone de Cicatrisation [Internet]. 2017 Jul;1(3):59-63. Available from: https://doi.org/10.1016/S2468-9114(17)30379-1 
3. Reid JD. Chronic Expanding Hematomas: A Clinicopathologic Entity. JAMA [Internet]. 1980 Nov 28 [cited 2021 Apr 24];244(21):2441. Available from: https://doi.org/10.1001/jama.1980.03310210043026

4. Gamo R, Vicente J, Calzado L, Sanz H, López-Estebaranz JL. Deep dissecting hematoma or stage IV dermatoporosis. Actas Dermosifiliogr [Internet]. 2010 Jan;101(1):89-90. Available from: https://doi.org/10.1016/j.ad.2009.04.002

5. Toutous Trellu L, Herrmann FR, Tarteaut M-H, Kaya A, Cheretakis A, Kaya G. Posttraumatic cutaneous hematomas in geriatrics hospital: A neglected disease? Eur Geriatr Med [Internet]. 2012 Apr;3(2):107-11. Available from: https://doi.org/10.1016/j.eurger.2012.01.005

6. Wettle C, Springinsfeld G, Lipsker D. Cutaneous haemorrhage induced by minimal trauma as a sign of light chain-associated amyloidosis. Br J Haematol [Internet]. 2012 Nov;159(4):383-383. Available from: https://doi.org/10.1111/bjh.12050

7. Inokuchi S, Nobeyama Y, Itoh M, Nakagawa H. A case of deep dissecting hematoma: different managements resulting in similar outcomes. Int J Dermatol [Internet]. 2016 Dec;55(12):e628-9. Available from: https://doi.org/10.1111/ijd.13390

8. Thomson WL, Pujol-Nicolas A, Tahir A, Siddiqui H. A kick in the shins: The financial impact of uncontrolled warfarin use in pre-tibial haematomas. Injury [Internet]. 2014 Jan;45(1):250-2. Available from: https://doi.org/10.1016/j.injury.2012.07.007

9. Suzuki H, Nobeyama Y, Sekiyama H, Kazama M, Tajima-Kondo S, Nakagawa H. Case of deep dissecting hematoma resulting in sepsis due to Pseudomonas aeruginosa infection. J Dermatol [Internet]. 2018 Mar;45(3):e65-6. Available from: https://doi.org/10.1111/1346-8138.14204

10. Kaya G, Saurat J-H. Dermatoporosis: A Chronic Cutaneous Insufficiency/Fragility Syndrome. Dermatology [Internet]. 2007;215(4):284-94. Available from: https://doi.org/10.1159/000107621

11. Mengeaud V, Dautezac-Vieu C, Josse G, Vellas B, Schmitt A-M. Prevalence of dermatoporosis in elderly French hospital in-patients: a cross-sectional study: Correspondence. British Journal of Dermatology [Internet]. 2012 Feb;166(2):442-3. Available from: https://doi.org/10.1111/j.1365-2133.2011.10534.x

12. Eicken JJ, Morrow D. Limb threatening thigh hematoma diagnosis accelerated by emergency physician bedside ultrasound. SAGE Open Med Case Rep [Internet]. 2019 Jan;7:2050313X1984858. Available from: https://doi.org/10.1177/2050313X19848589 


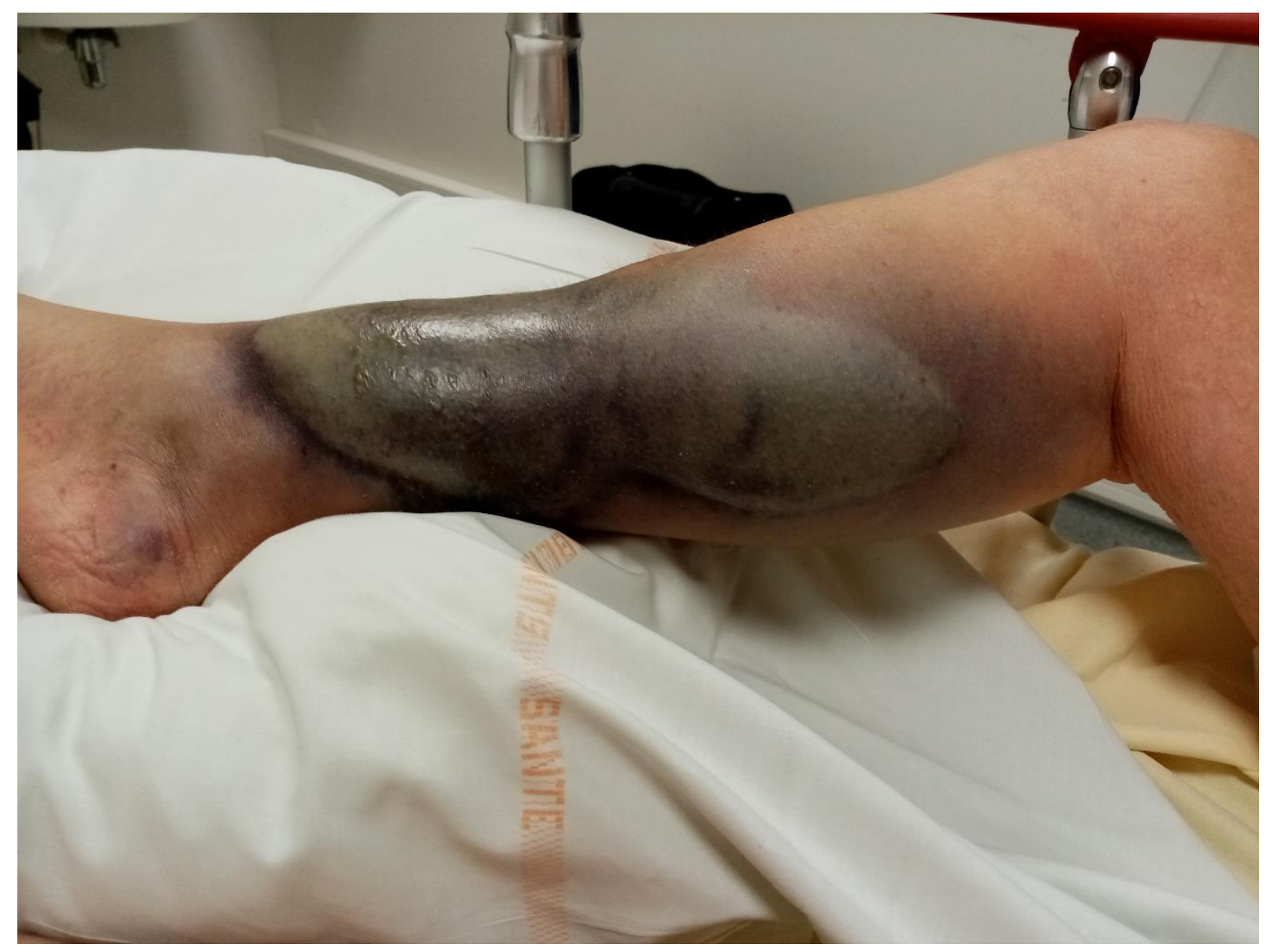

Figure 1. clinical presentation of the patient on admission, demonstrating a right-leg deep dissecting hematoma. 


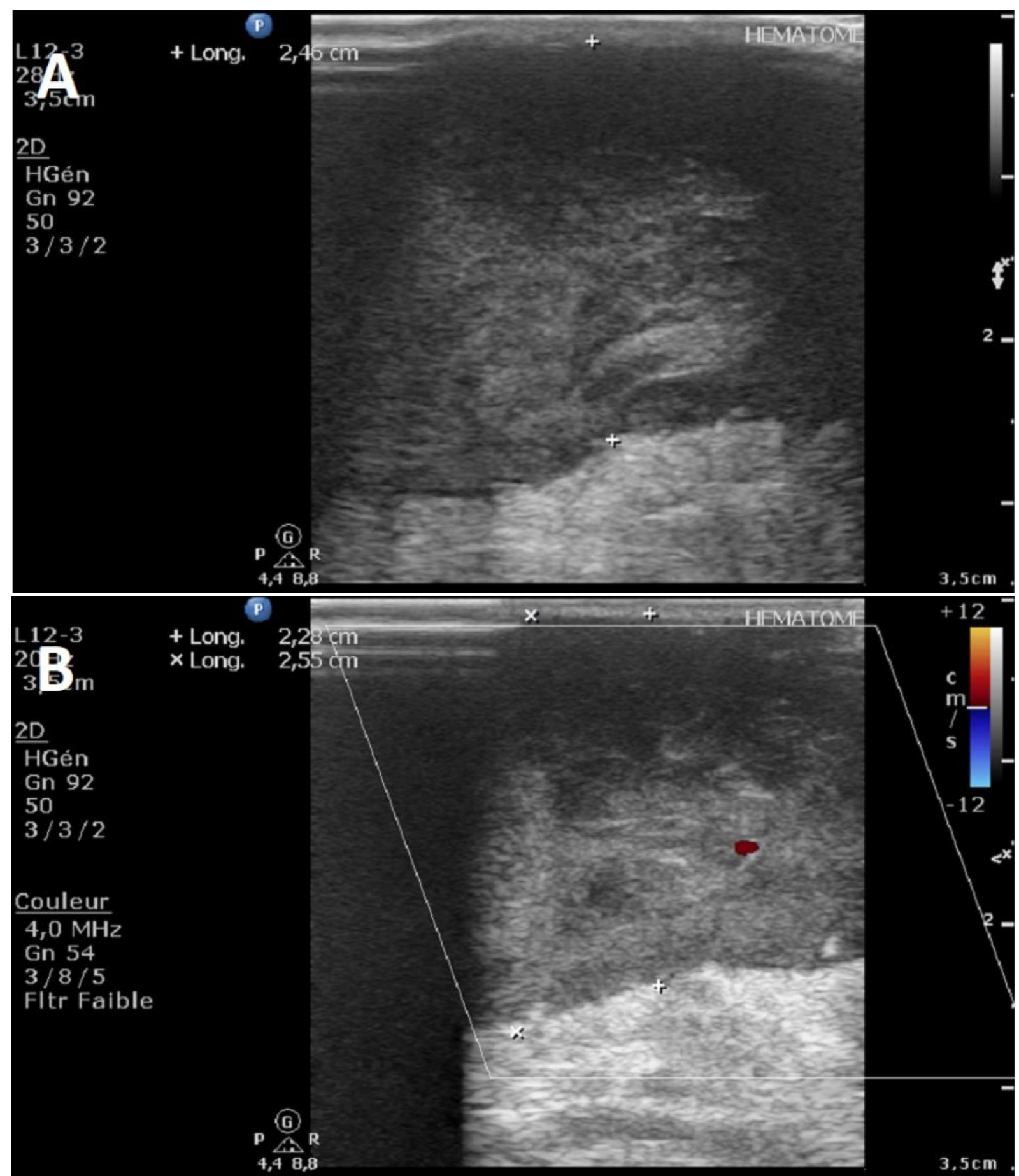

Figure 2. Images from the right-leg soft tissue US study. A longitudinal view of the hematoma, with detectable color flow at hematoma's checking. 